\title{
Hasenekevleri (Maden-Elazığ) Güneyindeki Diyabazlarda Gelişen Hidrotermal Cu Cevherleşmesinin Jeolojisi ve Alterasyon Jeokimyası
}

\author{
Cihan YALÇIN ${ }^{1 *}$, Mustafa KUMRAL ${ }^{2}$, Mustafa KAYA², Muhittin KARAMAN ${ }^{2}$ \\ ${ }^{1}$ Sanayi ve Teknoloji Bakanlığl, Sanayi Bölgeleri Genel Müdürlüğ̈̈, Ankara \\ ${ }^{2}$ Ístanbul Teknik Üniversitesi, Maden Fakültesi, Jeoloji Mühendisliği Bölümü, İstanbul \\ (ORCID: 0000-0002-0510-2992) (ORCID: 0000-0001-7827-8721) \\ (ORCID: 0000-0003-0694-9754) (ORCID: 0000-0002-8971-010X)
}

\begin{abstract}
$\ddot{\mathbf{O} z}$
Türkiye'nin en önemli bakır yataklarından biri olan Maden (Elazı̆̆) yatağı, Orta Eosen yaşlı Maden Grubuna ait litolojiler içerisinde yer alır. Maden grubu NW-SE ve NE-SW eğilimli faylar tarafindan kesilmiş volkanik ve tortul kayalardan oluşmaktadır. Maden (Elazığ) ilçesinin yaklaşık 12 km güneybatısında yer alan Hasenekevleri (MadenElazığ), Maden Grubuna ait diyabazlar içerisinde kırık hatlarında kuvars damarları ile ilişkili Cu zenginleşmelerine ev sahipliği yapar. Damar tipi ve epijenetik oluşumlu bu cevherleşme, ortalama $30 \mathrm{~m}$ genişliğinde ve $100 \mathrm{~m}$ uzunluğundadır. Cevher damarlarının kalınlığı 1-5 cm arasında değişmekte ve $\mathrm{Cu}$ konsantrasyonu \% 2.45'e (\% Ağırlık) ulaşmaktadır. Cevher süksesyonu pirit, kalkopirit, bornit, kovellit, götit ve malakit şeklindedir. Kırık hatları boyunca gelişen hidrotermal alterasyon sonucunda yan kayaçlarda serisitleşme, kloritleşme ve piritleşme yaygın olarak gözlenmektedir. Cevher zonunda hesaplanan (CIA) indeks değerleri; 15,72-85,90, klorit-karbonatpirit indeksi (CCPI) değerleri; 56,94-98,51 ve alterasyon indeksi (AI) değerleri 13,51-98,05 arasındadır. Cevher oluşumunun hidrotermal alterasyonların görüldüğü kırık hatlarında gözlenmesi cevherleşmede yapısal kontrolün etkin olduğunu göstermektedir.
\end{abstract}

Anahtar kelimeler: Maden grubu, epijenetik cu zenginleşmesi, hidrotermal alterasyon, yapısal kontrol, Hasenekevleri (Maden-Elazığ).

\section{Geology and Alteration Geochemistry of Hydrothermal $\mathrm{Cu}$ Mineralization in the Diabases to the Southern of Hasenekevleri (Maden-Elazığ)}

\begin{abstract}
Maden (Elazig) bed, one of Turkey's most important copper deposits, is located in the lithology of Middle Eocene aged Maden Group. Maden group consists of volcanic and sedimentary rocks, cut by NW-SE and NE-SW trending faults. Hasenekevleri (Maden-Elazığg), which is located about $12 \mathrm{~km}$ southwest of the mine (Elazığ) district, host the $\mathrm{Cu}$ enrichments associated with quartz veins in the fracture lines within the Maden Group diabases. The vein type and epigenetic mineralization is approximately $30 \mathrm{~m}$ wide and $100 \mathrm{~m}$ long. The thickness of the ore veins varies between $1-5 \mathrm{~cm}$ and the $\mathrm{Cu}$ concentration reaches $2.45 \%$. Ore succession is pyrite, chalcopyrite, bornite, covellite, goethite and malachite. As a result of hydrothermal alteration along the fracture lines, sericitization, chloritization and pyritization are common in the side rocks. In the ore zone, the calculated Chemical Alteration Index (CIA) value range is 15.72-85.90, the chloride-carbonate-pyrite index (CCPI) range value is 56.94-98.51 and the alteration index (AI) value range is 13.51-98.05. Observation of ore formation in fracture lines where hydrothermal alterations are observed shows that structural control is effective in mineralization.
\end{abstract}

Keywords: Maden group, epigenetic cu enrichment, hydrothermal alteration, structural control, Hasenekevleri (Maden-Elazığ).

\footnotetext{
*Sorumlu yazar: cihan.yalcin@sanayi.gov.tr

Geliş Tarihi: 07.10.2019, Kabul Tarihi: 09.04.2020
} 


\section{Giriş}

Türkiye'nin en önemli bakır yataklarından olan Maden (Elazığ) bakır yatağı M.Ö. 4000 yılı ile günümüze kadar birçok medeniyet tarafından işletilmiştir [1,2]. Bu bakır yatağ 1 ve civarında birçok jeolojik araştırmalar yapılmış [3-8] ve yatağın kökeni hakkında modeller ortaya konulmuştur [9-16]. Maden bakır yatağı Eosen çamurtaşları ve kloritleşmiş bazaltlar arasında ve tabakalı diyabaz daykları arasında bulunmaktadır $[13,17]$. Mineral parajenezi pirit, kalkopirit, sfalerit, manyetit ve ekzojenik bornite bağlı nabit bakırdan oluşmaktadır [18]. Bölgedeki diyabazlarda silisleşme, kloritleşme ve kaolenleşme yaygın olarak bulunmaktadır [18]. Maden bakır yatağı Kıbrıs tipi yataklanma göstermektedir [18].

Kıbrıs tipi masif sülfid yatakları (VMS) okyanus ortası sırtlarda magmatik aktivitedeki boşluk esnasında, hidrotermal suların sirkülasyonu sonucunda oluşmaktadır [19]. Sinjenetik oluşumlu kabul edilen bu yataklar erken evre piritleri bakımından zengindir. Kalkopirit, sfalerit ile birlikte altın ve kobalt mineralleri önemli seviyelere ulaşabilmektedir [18]. Richards vd., [20] parajenezde nabit bakır, ikincil bornit, markazit, galenit, hematit, stannit ve besteritin eser miktarda bulunduğunu, Yıldırım vd., [21] Türkiye'deki örneklerin manyetitçe zengin olduğunu ve Altun vd., [22] ise kobaltça zengin olduğunu belirtmişlerdir.

Türkiye'deki Kıbrıs tipi VMS yataklarının Orta Pontidlerde ve Bitlis-Zagros Sütur Zonu (BZSZ) boyunca geliştiği bilinmektedir [18]. Bu iki kuşakta yer alan Küre ve Maden (Elazığ) VMS yatakları antik dönemlerden beri işletilmektedir. Güneydoğu Anadolu kuşağında ise Orta Eosen yaşlı Maden ve Üst Triyas-Üst Kretase yaşlı Koçali komplekslerinde bulunmaktadır [23-29].

Maden (Elazığ) Bakır yatağının yaklaşık $12 \mathrm{~km}$ güneybatısında yer alan Hasenekevleri (MadenElazığ) bölgesinde diyabazlar içerisinde $\mathrm{Cu}$ zenginleşmeleri gelişmiştir. Bu bölgenin Maden (Elazığ) bölgesine yakın olması, benzer litoloji ve mineral parajenezinin gözlenmesi ve cevherleşmenin daha önce çalışılmamış olması sebebiyle, bu çalışmaya konu olan yatak üzerinde, saha ve laboratuvar çalışmaları gerçekleştirilmiştir.

\section{Materyal ve Metot}

Hasenekevleri (Maden-Elazığ) civarındaki birimlerin dokanak ilişkilerinin ortaya konulması amacıyla 1/25.000 ölçekli jeoloji haritası hazırlanmıştır. Cevherleşme bölgesinden derlenen örneklerin petrografi amaçlı ince ve parlak kesitleri İstanbul Teknik Üniversitesi Jeoloji Mühendisliği Bölümü ince kesit laboratuvarında hazırlanmış ve incelenmiştir.

Cevher ve alterasyon jeokimyası çalışmaları için ilk olarak, örnekler sırasıyla bir çeneli kırıcı ve bir çekiçli kırıcı kullanılarak ufalanmıştır. Daha sonra ufalanan numuneler, 24 saat boyunca $105^{\circ} \mathrm{Cde}$ bir firında kurutulmuştur. Kurutma işleminden sonra, 10-15 gr'lık numunelerin tane büyüklükleri, RETSCH (RS-200) model ögütme cihazı kullanılarak 177 um'ye düşürülmüştür. Ögü̈tme işlemi 1250 rpmde 1-2 dakika boyunca gerçekleştirilmiştir Tüm kurutulmuş ve toz haline getirilmiş numuneler nemden korunmak için bir kurutucuda saklanmıştır.

Hazırlanan örneklerin X-ray Fluorescence (XRF) analizleri BRUKER S8 TIGER model cihazda İstanbul Teknik Üniversitesi Jeokimya Araştırmaları Laboratuvarında (ITÜ̈-JAL) yapılmıştır.

\section{Jeoloji}

\subsection{Bölgesel Jeoloji}

BSZS Türkiye'nin güneydoğusunda yaklaşık olarak D-B uzanımlı bir hat boyunca gözlenmektedir (Şekil 1a). Paleotetis ve Neotetis okyanusal kabuklarına ait litolojilerden birini temsil eden bu kuşakta, Permiyen döneminde Gondwana ve Lavrasya kıtalarının çarpışması ile Neotetis okyanusu ile ilişkili kayaçlar yükselmiştir [30-33]. Orojenik kuşak kuzeyden güneye (Arabistan levhası) doğru bindirme zonları ile karakteristiktir [34-36].

Tektonik konum olarak Hasenekevleri (Maden-Elazığ) güneyindeki $\mathrm{Cu}$ zenginleşmesi, BitlisZagros Sütur Zonu (BSZS) kuzeyinde yer almaktadır (Şekil 1a). Bu bölgede İlk kez Ketin [37] tarafindan Ergani-Eğil dolaylarında "Maden serisi" olarak adlandırılan litostratigrafik birimler yer 
almaktadır. Güneydoğu Anadolu Orojenik kuşağınca gözlenen bu birimler için "Maden Kompleksi/Karmaşığı" [38-42] ve "Maden Grubu" ismi kullanılmıştır [3, 43].

Maden Grubu bazalt, bazaltik andezit, diyabaz, yastık lav, kumtaşı, şeyl, çamurtaşı ve kireçtaş1 bloklarından oluşmaktadır. Bu gruba ait kayaçlar 100-750 m arasında kalınlığa sahiptir [44]. Maden (Elazığ) bölgesinde ofiyolitler üzerine açısal uyumsuzlukla gelen bu birime ait volkanosedimanter istifler Arbo, Ceffan, Melafan ve Karadere formasyonu şeklinde dört formasyona ayrılmıştır [44]. Ertürk vd., [42] Maden Grubuna ait bazaltların Erken Kretase'ye kadar bir okyanus ortası sırtı boyunca MORB oluşumu ile yayıldığını, Geç Kretase' de okyanus içi yitimin başlaması ile ofiyolitler ve yay magmatitleri oluştuğunu belirtmiştir.

Paleontolojik çalışmalar Maden Grubunun yaşının Orta Eosen olduğunu [45], radyometrik yaşlar ise $48 \mathrm{Ma}$ (Orta Eosen) olduğunu [40] göstermektedir.

\section{2. Çalışma Alanının Jeolojisi}

İnceleme alanında Orta Eosen yaşl1 [45-46] Maden Grubuna ait birimler bulunmaktadır. Maden Grubu, alt volkano-sedimanter ve üst volkanik birimlerden oluşmaktadır [47]. Alt birim mafik volkanitler, çamurtaşları, pelajik kireçtaşları ve kireçtaşı bloklarından oluşmaktadır. Birbiri ile yanal-düşey geçişli olan bu birim üzerinde ise bazalt, andezit, diyabaz ve piroklastik kayaçlardan oluşan üst volkanik birimler gelir. Hasenekevleri civarında ve güneyinde Maden Grubuna ait birimler yüzlek vermektedir (Şekil 2). Tabandan tavana doğru istif incelendiğinde en altta bazalt mercekli sedimanter kayaçlar bulunmaktadır. Kirkor Tepesi ve Safi Sırtı boyunca gözlenen bu birimdeki sedimanter istif kiltaşı, çamurtaşı, kumtaşı ve pelajik kireçtaşından oluşmaktadır. İnceleme alanının büyük bir bölümünde gözlenen diyabaz ve spilitik bazaltlar, pelajik çamurtaşı, çamurtaşı ve kireçtaşı ile yanal düşey geçişlidir (Şekil 2). Düzeğeri Tepesi civarında ise dolomitik kireçtaşları açısal uyumsuzlukla tüm birimleri üzerlemektedir.

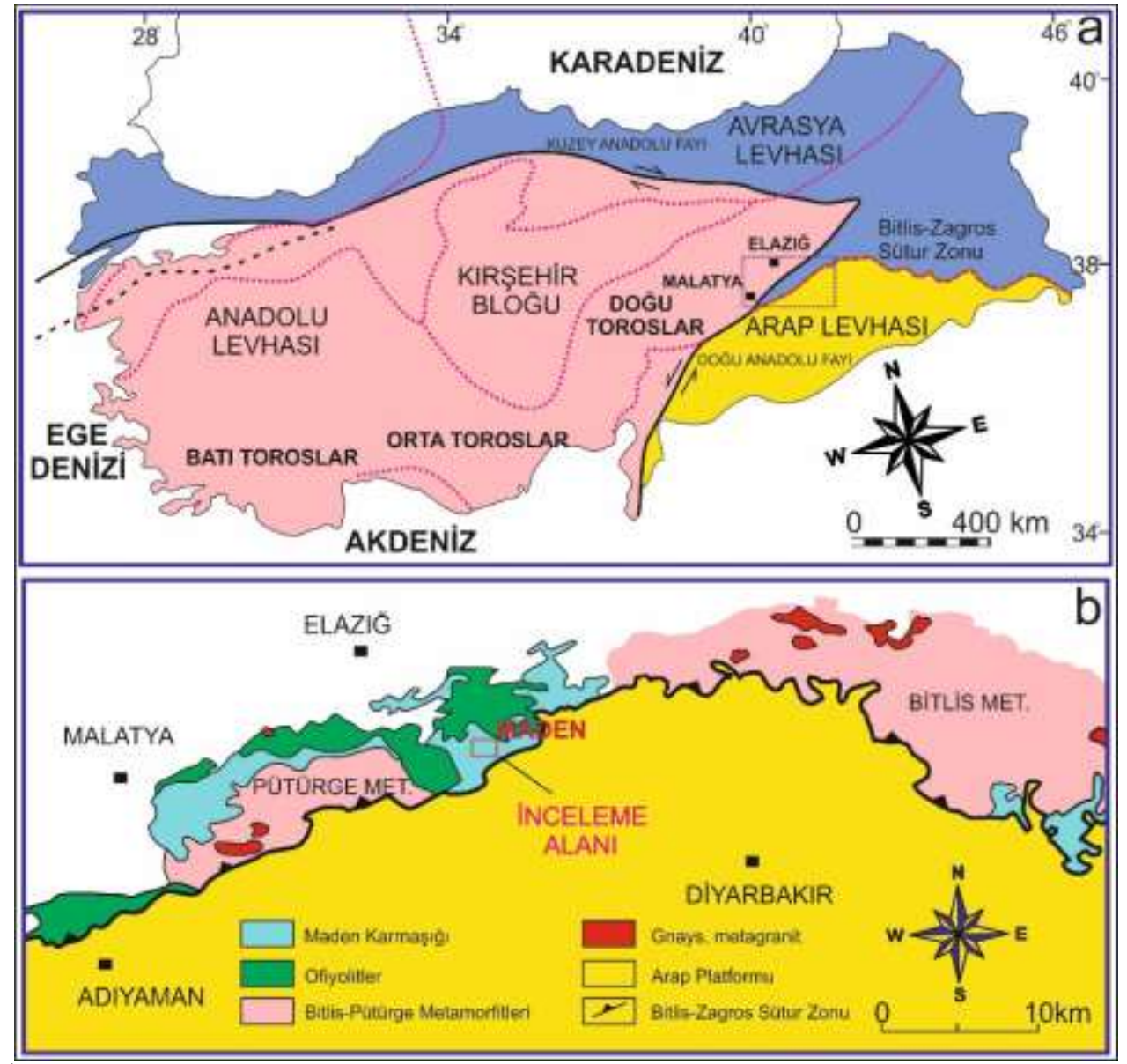

Şekil 1. a)İnceleme alanının tektonik konumu ve yer bulduru haritası (Işık, [48]'dan değiştirilmiştir), b) Çalışma alanı ve civarının jeoloji haritası (MTA, [49]'den değiştirilmiştir). 
Maden Grubuna ait birimler birçok alanda KD-GB ve KB-GD uzanımlı eğim atımlı faylar tarafindan kesilmektedir. Bu faylar boyunca gelişen ezik zonlarda ise ikincil kuvars damarları ve altere zonlar yaygin olarak görülmektedir.

Hasenekevleri güneyindeki Nava Tepesi güneybatısında yer alan diyabazlar içerisinde gelişmiş kırık zonlarında kuvars damarları ile ilişkili $\mathrm{Cu}$ cevherleşmeleri bulunmaktadır (Şekil 2).

\subsection{Cevherleşme}

İnceleme alanında geniş alanlarda yüzlek veren diyabazlar içerisindeki süreksizlik düzlemleri boyunca kuvars damarları yaygın olarak gözlenmektedir. $\mathrm{Bu}$ damarların yaygın gözlendiği alanlarda ise diyabazlar oldukça altere olmuştur (Şekil 3).

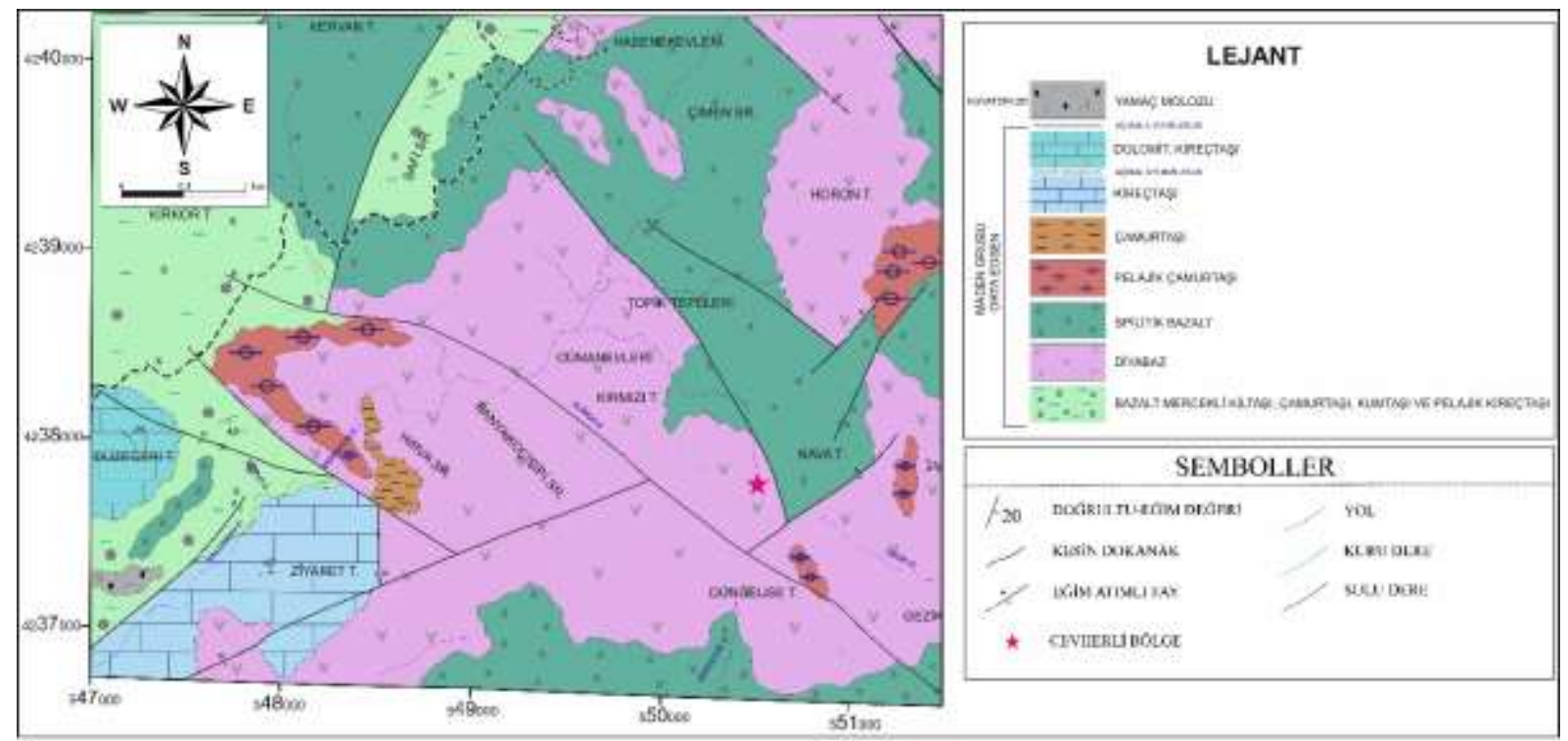

Şekil 2. İnceleme alanının 1/25.000 ölçekli jeoloji haritası

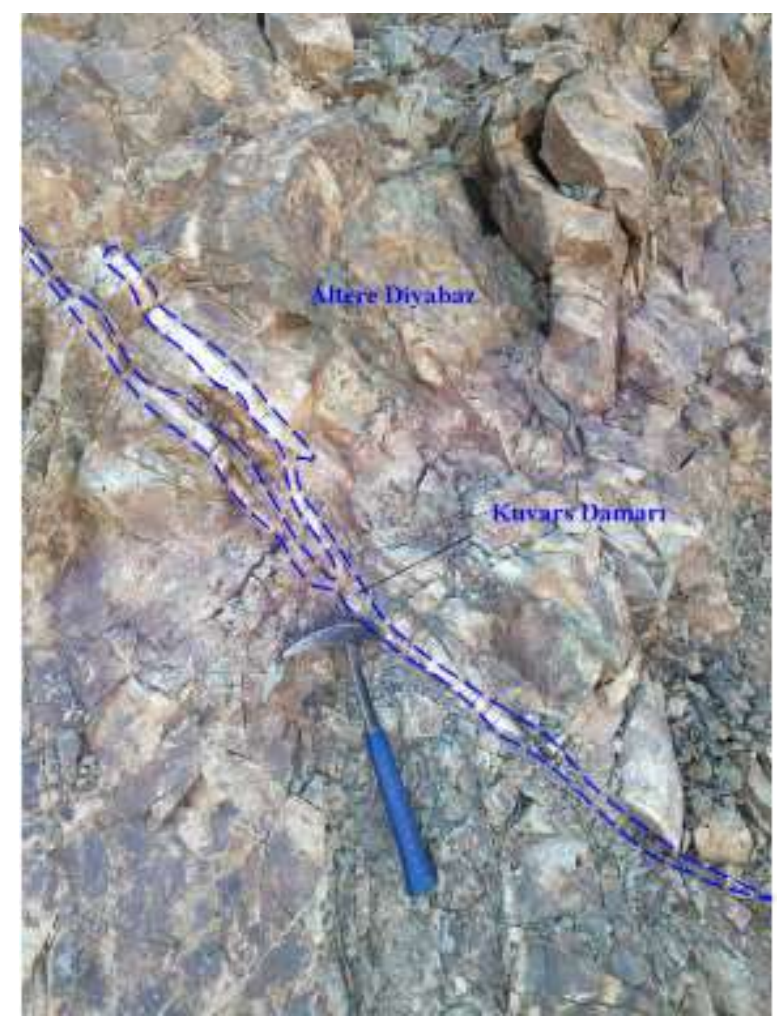

Şekil 3. İnceleme alanında altere diyabazlar ve kuvars damarlarının görünümü. 
Hasenekevleri güneyinde yer alan Nava Tepesi güneybatısındaki diyabazlar içerisinde ise kırık hatları ile ilişkili damar tipi $\mathrm{Cu}$ cevherleşmesi bulunmaktadır (Şekil 2). Kuvars damarları ile ilişkili ve epijenetik oluşumlu cevherleşme, ortalama $30 \mathrm{~m}$ genişliğinde $100 \mathrm{~m}$ uzunluğundadır. Cevher damarları 3-10 cm arasında değişmektedir. Damarın doğrultusu K30D şeklindedir. Eğimi ve eğim yönü ise 65 GD'dir. Alterasyonun yoğun olarak gözlendiği bu alanda kükürtlü zonlar (sarı zon) ile kilce zengin zonlar (gri zon) görülmektedir (Şekil 4).

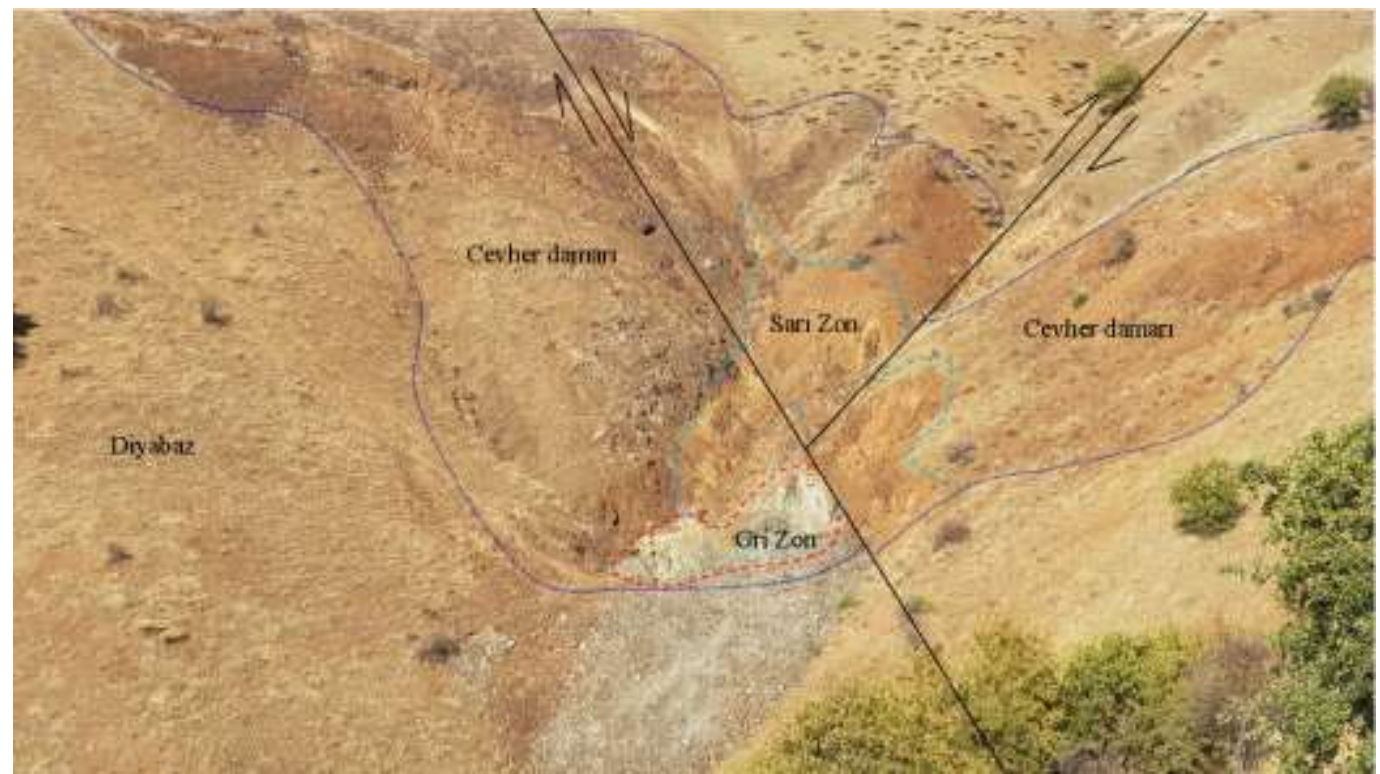

Şekil 4. İnceleme alanında Nava tepesi batısında yer alan cevher zonunun genel görünümü (Batıdan doğuya bakış)

\section{4. Örnekleme}

Nava Tepesi güneybatısında cevher damarı gözlenen diyabazlarda iki farklı zonda yüzey örnekleri alınmıştır. 1. zonda K75B doğrultusu boyunca 6 adet (Şekil 5), K40D doğrultusu boyunca 5 adet) ve 2. zonda ise K45D (Şekil 6) doğrultusu boyunca 13 adet örnek derlenmiştir. Örnekleme doğrultuları alterasyon, cevher damarı ve fay zonu dikkate alınarak gerçekleştirilmiştir.

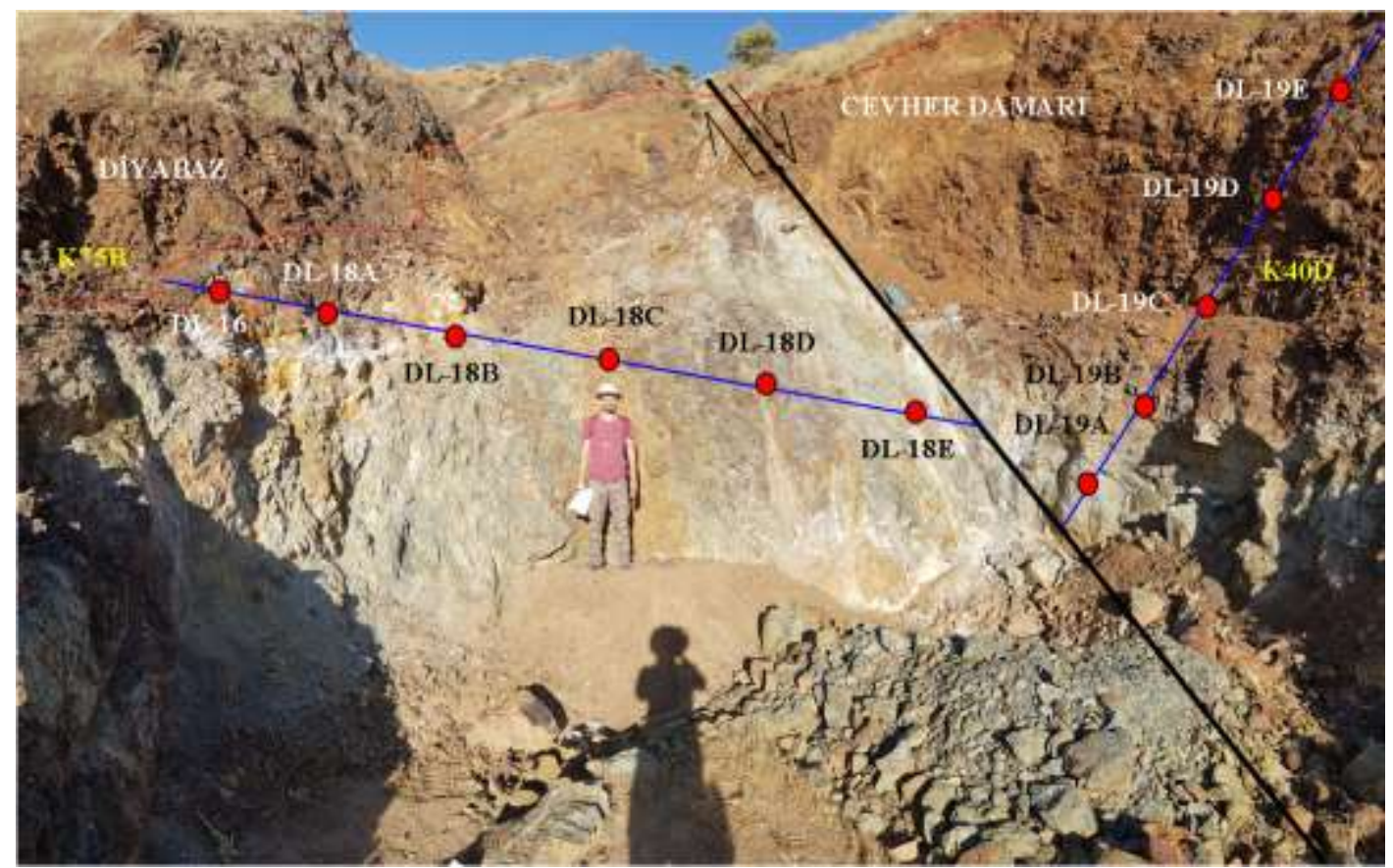

Şekil 5. 1. Zonda derlenen örneklerin noktaları ve örnek doğrultuları 


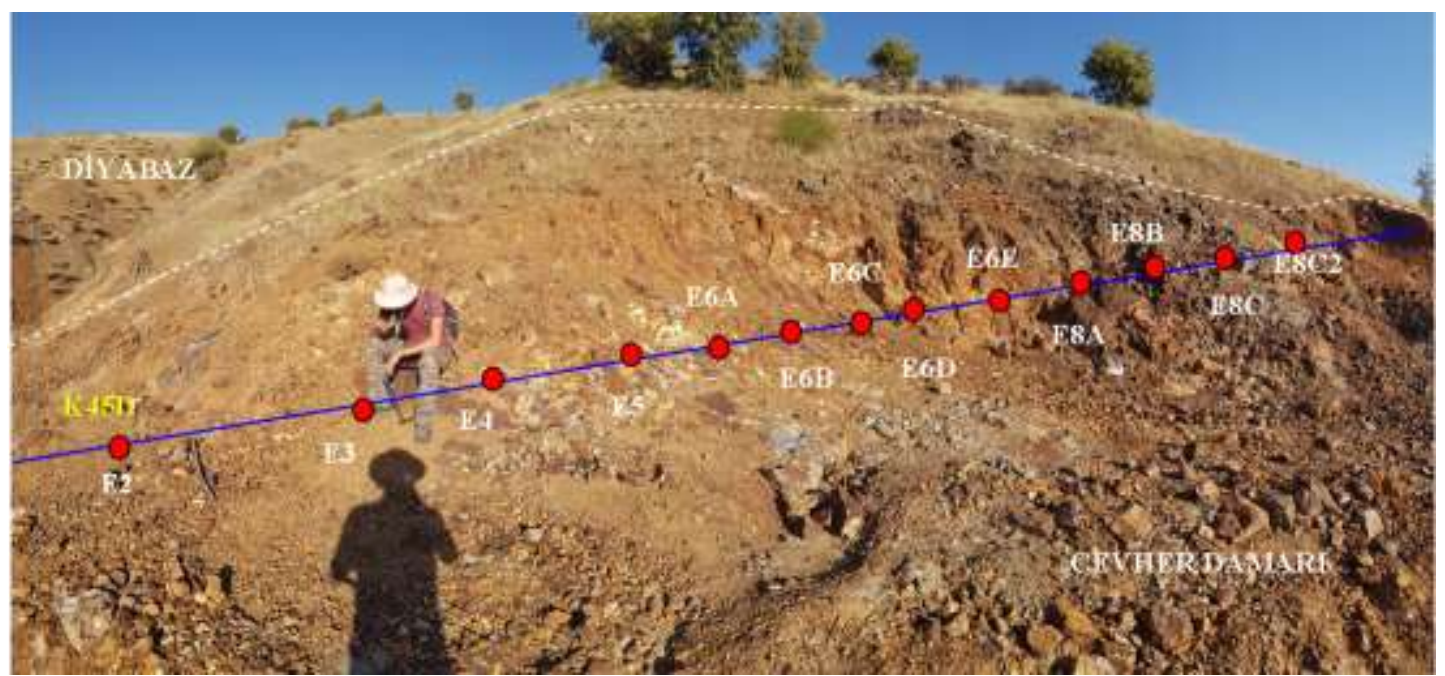

Şekil 6. 2. Zonda derlenen örneklerin noktaları ve örnek doğrultuları

\section{Bulgular ve Tartışma}

\subsection{Mineraloji ve Petrografi}

Cevher zonundaki diyabazların polarizan mikroskop incelemelerinde kayaç genel olarak subofitik dokuludur (Şekil 7a). Genel olarak kayaçta plajiyoklas, altere plajiyoklas, klinopiroksen, serisit, klorit, malakit, kuvars damarları ve opak mineraller yaygın olarak gözlenmektedir. Serisitleşme (Şekil 7b-d) ve kloritleşme (Şekil 7c) yaygın alterasyon mineralleridir. Kuvars damarları tarafından kesilen birim içerisinde ise kuvars damarları ile ilişkili opak mineraller bulunmaktadır (Şekil 7b-c-d).
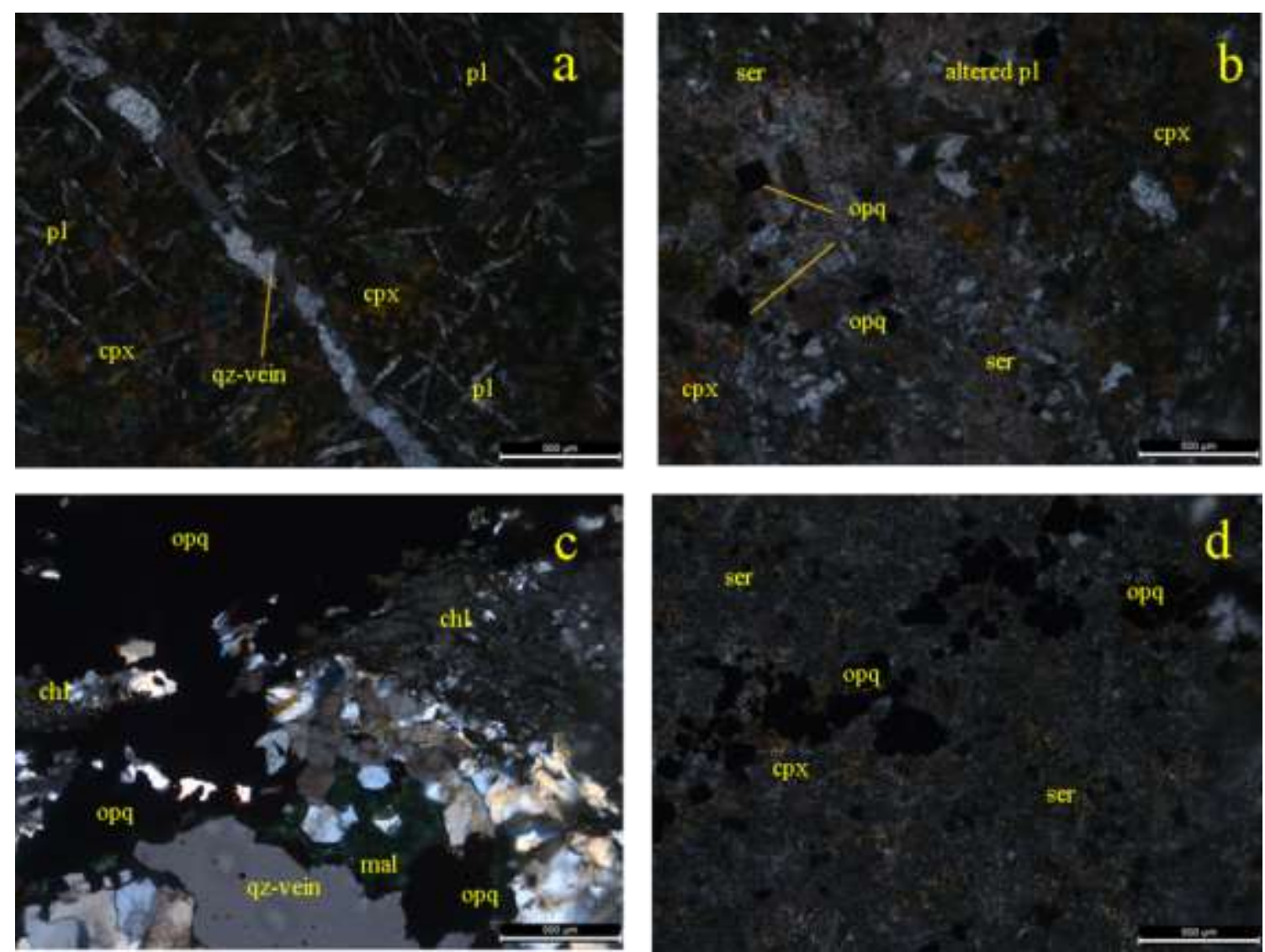

Şekil 7. Diyabazların polarizan mikroskop görüntüleri, a: b: c: d: hangi fotoğrafta ne var yazılmalıdır. pl: plajioklas, cpx: klinopiroksen, ser: serisit, altered pl: altere plajioklas, chl: klorit, mal: malakit, qz-vein: kuvars damar1, opq: opak mineral. 
Cevher mikroskobisi çalışmalarında ise başlıca pirit, kalkopirit, bornit, kovellit ve götit gözlenmiştir. Kalkopiritler bornite dönüşürken kovellit borniti ornatmaktadır (Şekil 8a). Piritlerde yer yer götit dönüşümü gözlenmekte olup bol piritli örneklerde pirit yüzeylerinin oldukça kirlendiği görülmektedir (Şekil 8b-c-d). Yapılan mikroskop çalışmaları sonucunda cevher minerallerinin diyabazları kesen kuvars damarları ile ilişkili olduğu belirlenmiştir.
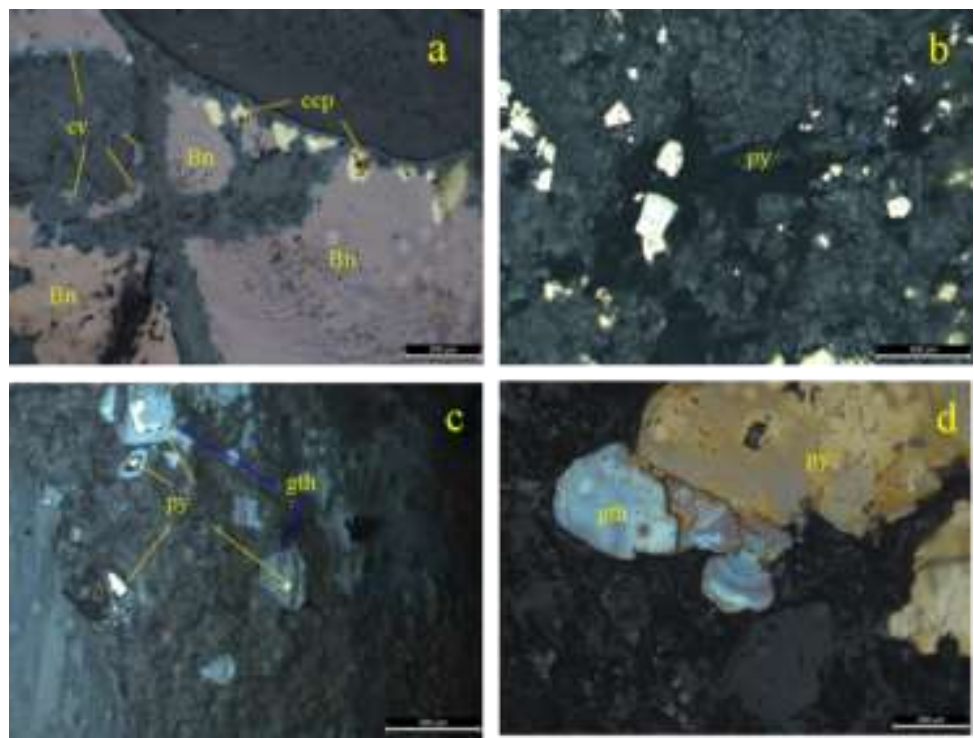

Şekil 8. Diyabazlar içerisinde gözlenen cevher minerallerine ait cevher mikroskobisi görüntüleri, Bn: bornit, ccp: kalkopirit, cv: kovellit, py: pirit, gth: götit.

Petrografik incelemeler cevher süksesyonunun pirit, bornit, kalkopirit, kovellit, götit ve malakit şeklinde olduğunu göstermektedir (Tablo 1).

Tablo 1. Cevherleşmenin parajenezi ve süksesyonu

\begin{tabular}{|l|r|l|}
\hline \multicolumn{1}{|c|}{ Mineraller } & $\begin{array}{c}\text { Cevher Minerallerinin } \\
\text { Oluştuğu Evre }\end{array}$ & Süperjen Evre \\
\cline { 2 - 3 } & & \\
\hline Pirit & & \\
\hline Kalkopirit & & \\
\hline Bornit & & \\
\hline Kovellit & & \\
\hline Malakit & & \\
\hline Götit & & \\
\hline
\end{tabular}

\subsection{Jeokimya}

Cevher zonunda iki farklı alanda farklı doğrultularda alınan örneklerin ana oksit element içerikleri Tablo 2 ve Tablo 3'de sunulmuştur. 1.zonda alınan örneklerin $\mathrm{SiO}_{2}$ değerleri \% 36,34-68,52 (\% ağırlık) arasında, $\mathrm{Al}_{2} \mathrm{O}_{3}$ değerleri \% 8,5-22,29 (\% Ağırlık) arasında, $\mathrm{Fe}_{2} \mathrm{O}_{3}$ değerleri \% 4,72-26,11 (\% Ağırlık) arasında $\mathrm{MgO}$ değerleri \%0,91-13,71 (\% Ağırlık) arasında ve $\mathrm{SO}_{3}$ değerleri ise \% 0,02-5,21 (\% Ağırlık) arasındadır. $\mathrm{Cu}$ değerleri de \% 0,01-0,03 (\% Ağırlık) arasında olup eser miktarda bulunmaktadır (Tablo 2).

2. Zonda alınan örneklerin $\mathrm{SiO}_{2}$ değerleri \% 15,72- 71,6 (\% Ağırlık) arasında, $\mathrm{Al}_{2} \mathrm{O}_{3}$ değerleri $\%$ 1,67-19,55 (\% A ğırlık) arasında, $\mathrm{Fe}_{2} \mathrm{O}_{3}$ değerleri \% 2,81-23,96 (\% Ă̆ırlık) arasında $\mathrm{MgO}$ değerleri $\%$ 1,67-12,21 (\% Ăğrlık) arasında ve $\mathrm{SO}_{3}$ değerleri ise \% 0,13-44,72 (\% Ağırlık) arasındadır. $\mathrm{Cu}$ maksimum \% 2,45 (\% Ağırlık) civarındadır (Tablo 3). Fay zonundan uzaklaştıkça Cu içeriğini arttığı, aşırı altere zonlarda $\mathrm{Cu}$ içeriğinin ise eser miktarda olduğu görülmektedir. 
Tablo 2. 1. Zonda alınan örneklerin XRF analizi sonuçları

\begin{tabular}{|c|c|c|c|c|c|c|c|c|c|c|c|}
\hline ÖRNEK & DL-16 & DL-18A & DL-18B & DL-18C & DL-18D & DL-18E & DL-19A & DL-19B & DL-19C & DL-19D & DL-19E \\
\hline \multicolumn{12}{|c|}{ MAJOR OKSITLER (\%) } \\
\hline $\mathrm{SiO}_{2}$ & 50,93 & 45,66 & 54,59 & 46,15 & 68,52 & 36,34 & 53,41 & 46,53 & 48,71 & 44,66 & 45,65 \\
\hline $\mathbf{A l}_{2} \mathbf{O}_{3}$ & 13,23 & 18,9 & 10,16 & 14,04 & 8,5 & 15,38 & 15,67 & 10,2 & 16,15 & 22,29 & 17,86 \\
\hline $\mathrm{Fe}_{2} \mathrm{O}_{3}$ & 7,71 & 7,3 & 9,88 & 10,62 & 4,72 & 13,44 & 9,21 & 26,11 & 12,65 & 17,15 & 16,15 \\
\hline MgO & 13,36 & 11,0 & 4,12 & 9,87 & 4,61 & 13,71 & 4,49 & 0,91 & 5,57 & 1,36 & 5,37 \\
\hline $\mathrm{CaO}$ & 0,54 & 0,8 & 16,26 & 7,44 & 0,42 & 2,98 & 1,78 & 0,02 & 0,98 & 0,3 & 0,14 \\
\hline $\mathrm{Na}_{2} \mathrm{O}$ & 0,34 & 2,1 & 0,36 & 0,8 & 2,2 & 1,88 & 1,65 & 0,06 & 0,4 & 0,09 & 0,34 \\
\hline $\mathbf{K}_{2} \mathbf{O}$ & 0,91 & 2,4 & 0,05 & 0,7 & 0,47 & 0,13 & 3,32 & 2,94 & 3,78 & 2,73 & 2,81 \\
\hline $\mathrm{TiO}_{2}$ & 0,41 & 0,6 & 1,09 & 0,56 & 0,26 & 1,03 & 1,42 & 2 & 1,1 & 1,14 & 1,67 \\
\hline MnO & 0,33 & 0,3 & 0,28 & 0,51 & 0,11 & 0,49 & 0,15 & 0,01 & 0,18 & 0,02 & 0,22 \\
\hline $\mathrm{SO}_{3}$ & 4,06 & 3,3 & 0,02 & 2,56 & 5,21 & 4,77 & 2,48 & 1,61 & 2,61 & 0,11 & 0,44 \\
\hline $\mathbf{P}_{2} \mathbf{O}_{5}$ & 0,15 & 0,2 & 0,09 & 0,16 & 0,09 & 0,61 & 0,67 & 0,52 & 0,56 & 0,15 & 0,37 \\
\hline $\mathrm{Cr}_{2} \mathrm{O}_{3}$ & 0,18 & 0,1 & 0,61 & 0,04 & 0,15 & 0,21 & 0,4 & 0 & 0 & 0 & 0,45 \\
\hline $\mathbf{C u}$ & 0,03 & 0,01 & 0,01 & 0,01 & 0,01 & 0,01 & 0,01 & 0,02 & 0,03 & 0,03 & 0,01 \\
\hline LOI & 7,63 & 7,09 & 2,18 & 6,3 & 4,62 & 8,86 & 4,98 & 8,8 & 6,88 & 9,67 & 8,01 \\
\hline
\end{tabular}

Tablo 3. 2. Zonda alınan örneklerin XRF analizi sonuçları

\begin{tabular}{|c|c|c|c|c|c|c|c|c|c|c|c|c|c|}
\hline ÖRNEK & E2 & E3 & E4 & E5 & E6A & E6B & E6C & E6D & E6E & E8A & E8B & E8C & E8C2 \\
\hline \multicolumn{14}{|c|}{ MAJOR OKSİTLER (\%) } \\
\hline $\mathrm{SiO}_{2}$ & 53,65 & 55,42 & 71,6 & 52,41 & 56,07 & 36,34 & 62,45 & 54,44 & 15,72 & 69,05 & 61,54 & 53,1 & 57,48 \\
\hline $\mathbf{A l}_{2} \mathbf{O}_{3}$ & 17,39 & 13,4 & 10,61 & 19,55 & 12,06 & 12,66 & 10,04 & 12,96 & 5,39 & 13,63 & 1,67 & 14,81 & 14,39 \\
\hline $\mathrm{Fe}_{2} \mathrm{O}_{3}$ & 6,73 & 6,5 & 2,34 & 8,2 & 8,5 & 7,86 & 6,22 & 8,69 & 23,96 & 2,81 & 7,71 & 9,13 & 6,14 \\
\hline MgO & 3,61 & 3,1 & 2,27 & 5,89 & 12,21 & 5,29 & 2,92 & 12,37 & 3,79 & 4,68 & 1,67 & 2,52 & 4,25 \\
\hline $\mathrm{CaO}$ & 4,52 & 8,0 & 5,9 & 0,09 & 0,26 & 1,49 & 0,18 & 0,45 & 0,13 & 0,61 & 11,52 & 12,04 & 0,28 \\
\hline $\mathrm{Na}_{2} \mathrm{O}$ & 7,16 & 3,2 & 3,21 & 0,29 & 0 & 1,35 & 1,01 & 1,03 & 0 & 2,84 & 0 & 3,35 & 0,14 \\
\hline $\mathbf{K}_{2} \mathbf{O}$ & 0,15 & 1,1 & 0,03 & 3,63 & 0,84 & 2,14 & 1,93 & 0,26 & 0,73 & 1,7 & 0,13 & 0,04 & 3,81 \\
\hline $\mathrm{TiO}_{2}$ & 0,98 & 1,1 & 0,83 & 1,01 & 0,5 & 1,14 & 0,36 & 0,54 & 0,11 & 0,46 & 0,05 & 0,85 & 0,48 \\
\hline MnO & 0,19 & 0,3 & 0,04 & 0,23 & 0,22 & 0,31 & 0,05 & 0,3 & 0,04 & 0,14 & 0,1 & 0,18 & 0,19 \\
\hline $\mathrm{SO}_{3}$ & 0,23 & 0,9 & 0,13 & 1,44 & 2,79 & 0,7 & 7,86 & 2,49 & 44,72 & 0,72 & 10,54 & 0,02 & 4,98 \\
\hline $\mathbf{B a}$ & - & - & 0,18 & 0,07 & - & - & 0,24 & - & - & 0,12 & - & - & 0,31 \\
\hline $\mathbf{P}_{2} \mathbf{O}_{5}$ & 0,22 & 0,4 & 0,32 & 0,18 & 0,11 & 0,46 & 0,08 & 0,13 & 0,07 & 0,22 & 0 & 0,47 & 0,1 \\
\hline $\mathrm{Sr}$ & - & - & 0,05 & - & - & - & - & - & - & - & - & 0,17 & - \\
\hline $\mathrm{Cu}$ & 1,07 & 2,45 & 0,20 & 0,02 & - & 0,01 & - & - & $\mathbf{0 , 0 1}$ & 0,01 & - & 0,56 & - \\
\hline $\mathrm{Cr}_{2} \mathrm{O}_{3}$ & 0,45 & 0,4 & 0 & 0,2 & 0,47 & 0 & 0,08 & 0,06 & 0,32 & 0,25 & 0 & 0,01 & 0,13 \\
\hline LOI & 3,25 & 2,96 & 2,23 & 6,55 & 5,8 & 29,41 & 6,48 & 6,2 & 4,91 & 2,73 & 4,99 & 2,32 & 7,26 \\
\hline
\end{tabular}




\subsection{Alterasyon Jeokimyası}

Yapılan saha ve laboratuvar çalışması sonucunda Nava Tepesi güneybatısında gözlenen altere zonlardaki mineralojik ve kimyasal değişimleri belirlemek amaciyla,

1- Klorit-karbonat-pirit indeksi [50-51] $\left(\mathrm{CCPI}=100\left(\mathrm{MgO}+\mathrm{FeO}^{*}\right) /\left(\mathrm{MgO}+\mathrm{FeO}^{*}+\mathrm{Na}_{2} \mathrm{O}+\mathrm{K}_{2} \mathrm{O}\right)\right.$,

2- Kimyasal alterasyon indeksi [52] $\left(\mathrm{CIA}=\right.$ molar $\left.\mathrm{Al}_{2} \mathrm{O}_{3} /\left(\mathrm{Al}_{2} \mathrm{O}_{3}+\mathrm{CaO}^{*}+\mathrm{Na}_{2} \mathrm{O}+\mathrm{K}_{2} \mathrm{O}\right) \times 100\right)$,

3- Alterasyon indeksi [50-51] $\left(\mathrm{AI}=100\left(\mathrm{~K}_{2} \mathrm{O}+\mathrm{MgO}\right) /\left(\mathrm{K}_{2} \mathrm{O}+\mathrm{MgO}+\mathrm{Na}_{2} \mathrm{O}+\mathrm{CaO}\right)\right.$ hesaplanmıştır (Tablo 4).

İndeks değerleri (CIA); 15,72-85,90, klorit-karbonat-pirit indeksi (CCPI) değerleri; 56,94-98,51 ve alterasyon indeksi (AI) değerleri ise 13,51-98,05 arasındadır.

Kaolenit ve klorit gibi fillosilikatların CIA değeri 95-100, diğer killerden simektit ve illitin CIA değeri 75-85 aralığındadır [52]. CIA değerlerine göre fay zonu boyunca (1. Zon) orta dereceli ayrışma (CIA: 64,5-68,1), cevherleşme bölgesinde ise orta (CIA: 65-85) ve ileri dereceli (CIA > 85) ayrışma gerçekleşmiştir.

A-CN-K $\left(\mathrm{Al}_{2} \mathrm{O}_{3}-\mathrm{CaO}^{*}+\mathrm{Na}_{2} \mathrm{O}-\mathrm{K}_{2} \mathrm{O}\right.$ ) diyagramında [53] (Şekil 9) 1.Örnekleme zonuna ait örneklere göre, $\mathrm{K}$-feldispat büyük oranda alterasyona uğrayarak fillosilikata (illit) dönüşmüş ve ortamda $\mathrm{K}_{2} \mathrm{O}$ azalırken $\mathrm{Al}_{2} \mathrm{O}_{3}$ miktarı artmıştır (Şekil 9a). 2. Örnekleme zonuna göre ise $\mathrm{Ca}_{2} \mathrm{O}$ ve $\mathrm{Na}_{2} \mathrm{O}$ azalırken, $\mathrm{K}_{2} \mathrm{O}$ ve $\mathrm{Al}_{2} \mathrm{O}_{3}$ artmış ve feldispatlar (plajiyoklas) muskovite-illite (serisite) dönüşmüştür. Alterasyonun ileri evresinde ise $\mathrm{K}_{2} \mathrm{O}$ azalarak ortamda $\mathrm{Al}_{2} \mathrm{O}_{3}$ artmıştır (Şekil 9a).

A-CNK-FM $\left(\mathrm{Al}_{2} \mathrm{O}_{3}-\mathrm{CaO}^{*}+\mathrm{Na}_{2} \mathrm{O}+\mathrm{K}_{2} \mathrm{O}-\mathrm{FeO}^{*}+\mathrm{MgO}\right)$ [53] diyagramında 1.Örnekleme zonunda $\mathrm{Fe}_{2} \mathrm{O}_{3}$ ve $\mathrm{MgO}$ 'in (FM) toplamı $\mathrm{Ca}_{2} \mathrm{O}, \mathrm{Na}_{2} \mathrm{O}$ ve $\mathrm{K}_{2} \mathrm{O}$ 'e (CNK) göre artmış, kloritleşmeye doğru eğilim gerçekleşmiştir (Şekil 9b). 2. Örnekleme zonunda ise $\mathrm{Fe}_{2} \mathrm{O}_{3}$ ve $\mathrm{MgO}$ miktarı alterasyonla birlikte artmış ve serisitler kloritleşmiştir (Şekil 9b).

Elde edilen indeks değerleri $\mathrm{K}_{2} \mathrm{O}-\mathrm{AI}$ (Şekil 10a) ve $\mathrm{Na}_{2} \mathrm{O}-\mathrm{AI}$ (Şekil 10b) diyagramlarında değerlendirilmiştir. Her iki örnek zonunda da alterasyon eğiliminin kloritleşme ve serisitleşmeye doğru ilerlediği ve alterasyonda hidrotermal akışkanların etkili olduğu [51] görülmektedir.

Na-Plajiyoklasların alterasyonu sırasında meydana gelen iyon değişimi nedeni ile alterasyonun şiddeti arttıkça \% $\mathrm{Na}_{2} \mathrm{O}$ azalmaktadır $\left(\mathrm{R}^{2}=0.84\right)$ (Şekil 11a). Serisitin klorite oranına bağlı olarak artan $\mathrm{K}_{2} \mathrm{O}$ miktarı da, $\mathrm{AI}$ indeksi ile de ilişkilidir $\left(\mathrm{R}^{2}=0.98\right)($ Şekil $11 \mathrm{~b})$.

CCPI-AI diyagramında ise (Şekil 12) iki zona ait örneklerin hidrotermal ayrışma alanında [51] ve yaygın alterasyon eğiliminin ise klorit+pirit+serisit şeklinde olduğu görülmektedir.

\subsection{Tartışma}

Kıbrıs tipi VMS yataklarından olan Maden (Elazığ) bölgesine yakın olması sebebiyle Hasenekevleri (Maden-Elazığg) güneyindeki $\mathrm{Cu}$ cevherleşmesinin jeokimyasal özelliklerinin belirlenmesi önemlidir. Maden (Elazığ) bölgesinde yapılmış çalışmalarda iki farklı tip $\mathrm{Cu}$ mineralizasyonu oluşumundan bahsedilmektedir [54]. Aynı yazarlar tarafindan iki farklı tipteki yatak, mineral parajenezi ve alterasyon mineralojisi araştırılarak karşılaştırılmıştır. Zahuran bölgesinde (Maden-Elazığ) diyabazlar içerisinde gelişen fay zonları ile ilişkili $\mathrm{Cu}$ zenginleşmelerinin olduğu ve epijenetik hidrotermal cevherleşmede alterasyonların görüldüğü belirtilmiştir [54]. Bu çalışmada da benzer şekilde mineral parajenezi ve alterasyon mineralojisi karşılaştırılmıştır.

Maden (Elazığ) bakır yatağı Eosen yaşı Maden grubuna ait çamurtaşları ve kloritleşmiş bazaltlar arasında ve tabakalı diyabaz daykları arasında [13,17], Hasenekevleri güneyindeki cevherleşme ise diyabazlar içerisinde bulunmaktadır.

Maden yatağının mineral parajenezi pirit, kalkopirit, sfalerit, manyetit ve ekzojenik bornite bağlı nabit bakırdan oluşmakta [18] Hasenekevleri güneyinin ise pirit, bornit, kalkopirit, kovellit, götit ve malakitten oluşmaktadır.

Maden yatağında diyabazlarda silisleşme, kloritleşme ve kaolenleşme yaygın olarak gözlenmekte [18] iken Hasenekevleri güneyinde kloritleşme, piritleşme ve serisitleşme yaygındır. Cevher zonunda yapılan alterasyon jeokimyası çalışmalarında indeks değerleri (CIA); 15,72-85,90, klorit-karbonat-pirit indeksi (CCPI) değerleri; 56,94-98,51 ve alterasyon indeksi (AI) değerleri ise 13,51-98,05 arasındadır. Bu değerler CCPI-AI diyagramında hidrotermal ayrışma alanında yoğunlaşmış [51] ve yaygın alterasyon eğiliminin ise klorit+ pirit+serisit şeklinde olduğu belirlenmiştir. 
Kıbrıs Tipi VMS yataklarının sinjenetik oluşumlu olduğu kabul edilmektedir. Ancak Hasanekevleri güneyindeki cevherleşme diyabazlarda gelişmiş kırık hatlarındaki kuvars damarları ile ilişkilidir ve epijenetik oluşumludur.

İnceleme alanına yakın alanda gözlenen Zahuran (Maden-Elazığ) bölgesindeki damar tipi cevherleşmelerin en azından bir kısmının daha önceden oluşmuş volkano-sedimanter tipdeki cevher zonlarından katyonlar ile kırık hatlarında hareket ederek diyabazlardaki ezik zonlara yerleşebileceği öne sürülmüştür [54]. Hasenekevleri güneyindeki $\mathrm{Cu}$ cevherleşmesi de benzer özellikler göstermektedir.

Tablo 4. Cevher zonunda hesaplanan alterasyon indeks değerleri

\begin{tabular}{cccc}
\hline Örnek & CIA & CCPI & AI \\
\hline DL-16 & 68,5 & 94,20 & 94,19 \\
DL-18A & 85,9 & 79,55 & 82,25 \\
DL-18B & 72,8 & 96,94 & 20,06 \\
DL-18C & 25,3 & 92,83 & 56,19 \\
DL-18D & 48,0 & 76,84 & 65,97 \\
DL-18E & 64,5 & 92,77 & 74,01 \\
DL-19A & 68,1 & 72,00 & 69,48 \\
DL-19B & 66,4 & 89,05 & 97,96 \\
DL-19C & 83,1 & 80,22 & 87,14 \\
DL-19D & 75,7 & 85,62 & 91,29 \\
DL-19E & 87,1 & 86,34 & 94,46 \\
E2 & 53,65 & 56,94 & 24,35 \\
E3 & 55,42 & 67,58 & 27,23 \\
E4 & 71,6 & 57,46 & 20,16 \\
E5 & 52,41 & 77,19 & 96,16 \\
E6A & 56,07 & 95,94 & 98,05 \\
E6B & 36,34 & 77,98 & 72,35 \\
E6C & 62,45 & 74,34 & 80,30 \\
E6D & 54,44 & 93,99 & 89,51 \\
E6E & 15,72 & 97,20 & 97,20 \\
E8A & 69,05 & 61,36 & 64,90 \\
E8B & 61,54 & 98,51 & 13,51 \\
E8C & 53,1 & 76,00 & 14,26 \\
E8C2 & 57,48 & 71,22 & 95,05 \\
E8C2 & 57,48 & 71,22 & 95,05 \\
\hline
\end{tabular}




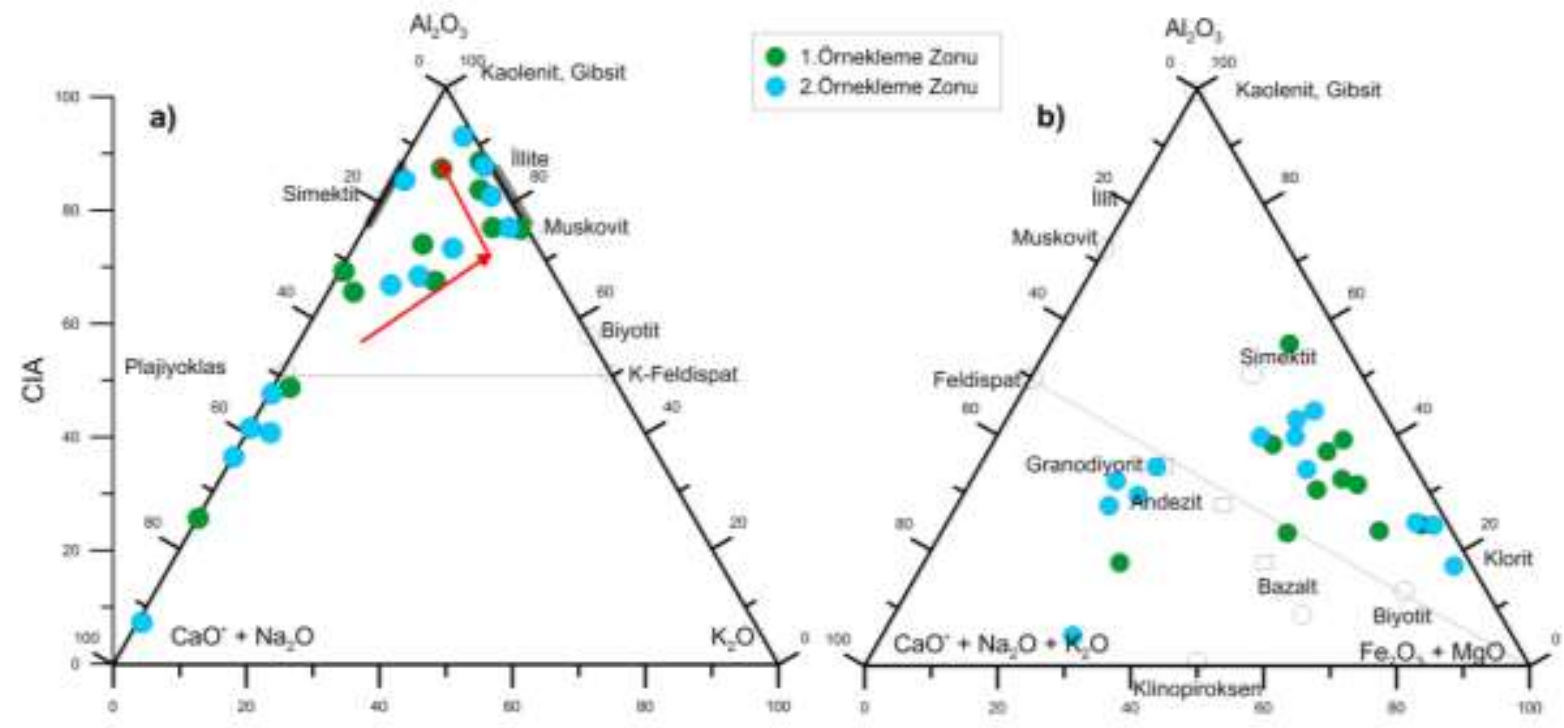

Şekil 9. Hasanekevleri cevher zonlarındaki örnekler için, (a) A-CN-K $\left(\mathrm{Al}_{2} \mathrm{O}_{3}-\mathrm{CaO}^{*}+\mathrm{Na} 2 \mathrm{O}-\mathrm{K}_{2} \mathrm{O}\right)$ ve (b) A-CNK$\mathrm{FM}\left(\mathrm{Al}_{2} \mathrm{O}_{3}-\mathrm{CaO}^{*}+\mathrm{Na}_{2} \mathrm{O}+\mathrm{K}_{2} \mathrm{O}-\mathrm{FeO}^{*}+\mathrm{MgO}\right)$ diyagramları.
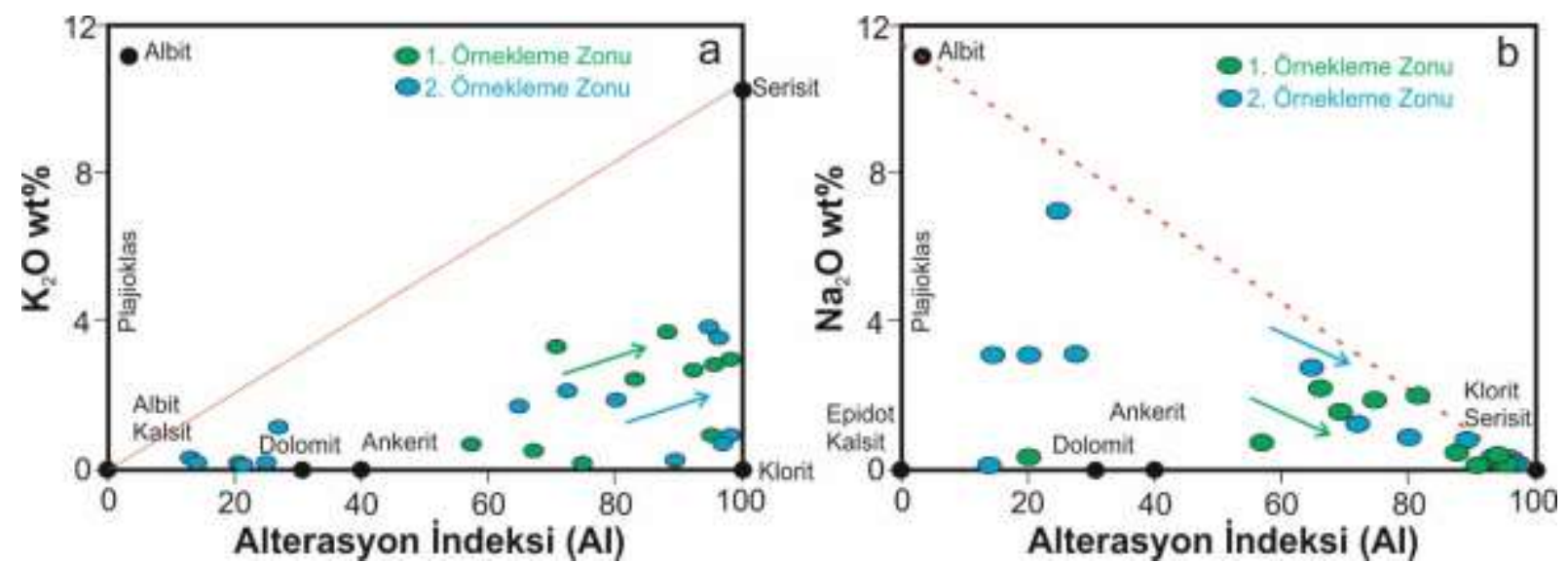

Şekil 10. a. Hasanekevleri cevher zonlarındaki örnekler için, $\mathrm{K}_{2} \mathrm{O}-\mathrm{AI}$ diyagramı, b. $\mathrm{Na}_{2} \mathrm{O}-\mathrm{AI}$ diyagramı.
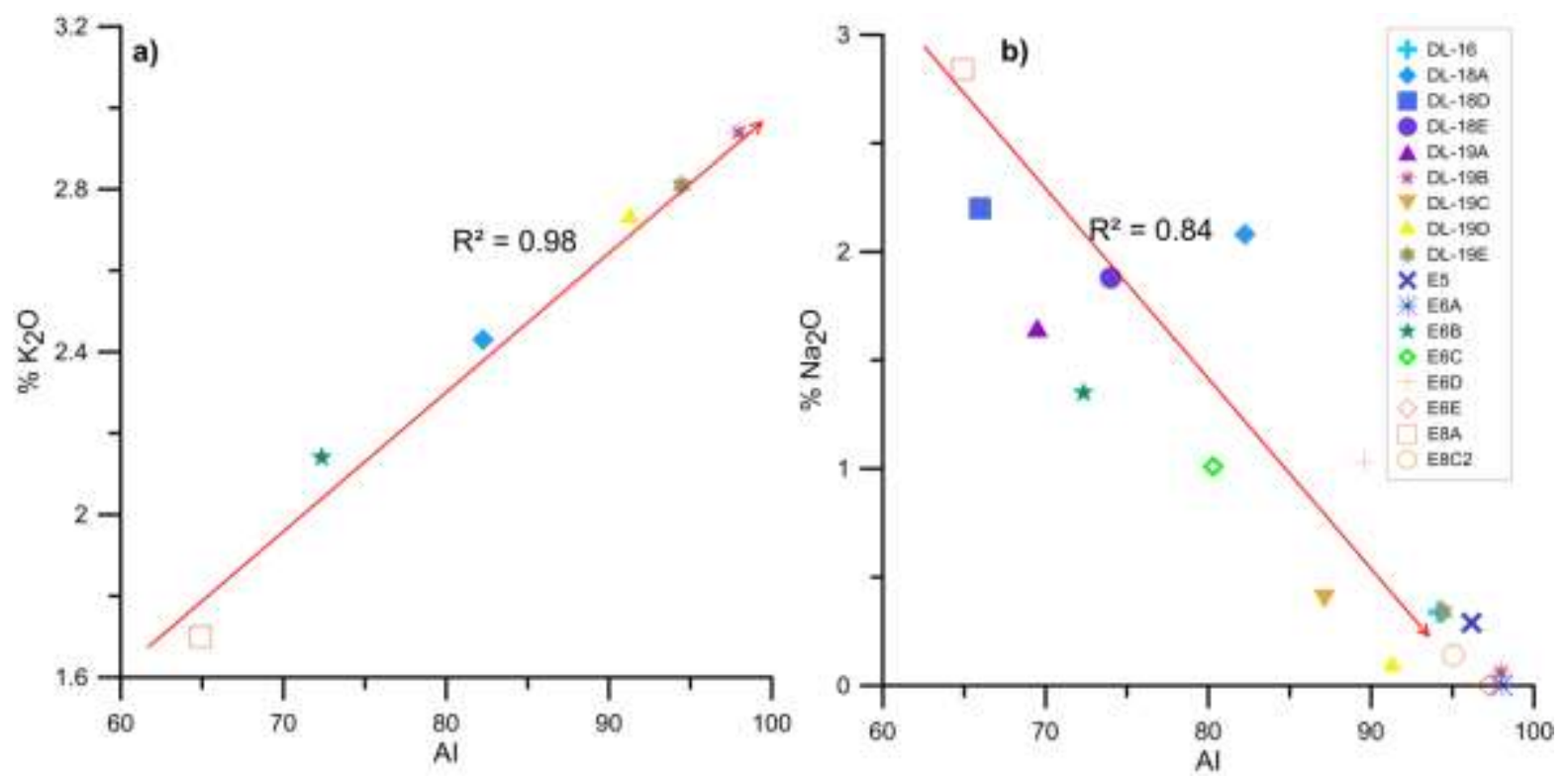

Şekil 11. a. Hasanekevleri cevher zonlarındaki örnekler için, $\mathrm{K}_{2} \mathrm{O}-\mathrm{AI}$ diyagramı, b. $\mathrm{Na}_{2} \mathrm{O}-\mathrm{AI}$ diyagramı. 


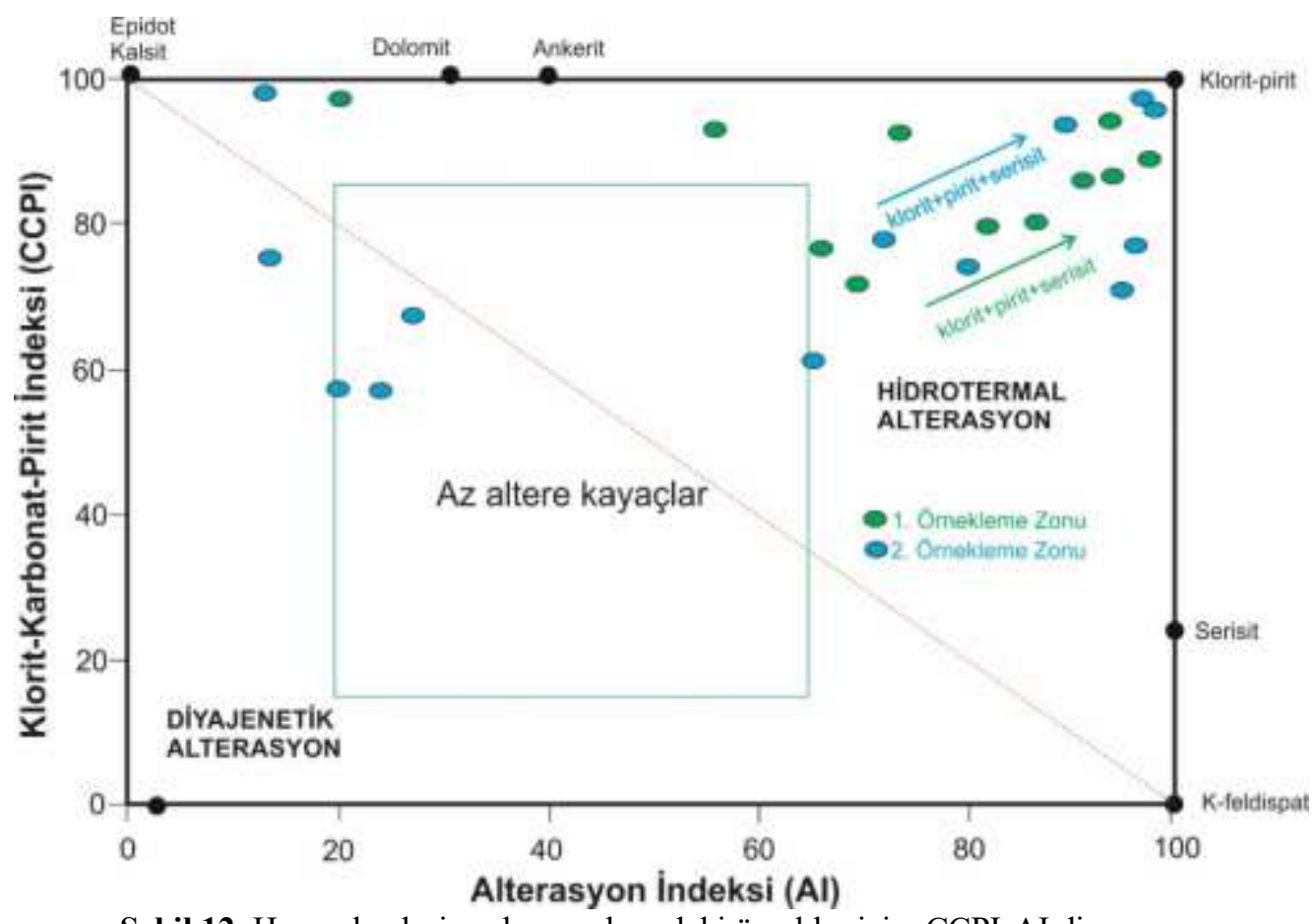

Şekil 12. Hasanekevleri cevher zonlarındaki örnekler için, CCPI-AI diyagramı.

\section{Sonuç ve Öneriler}

Hasenekevleri (Maden-Elazığ) güneyindeki Nava Tepesi batısında yer alan Orta Eosen yaşlı Maden Grubuna ait diyabazlar içerisinde gelişen fay zonları ve eklemlerde kuvars damarları gözlenmektedir. $\mathrm{Bu}$ damarlar ile ilişkili cevher mineralleri de gelişmiştir.

Yapılan petrografi ve jeokimya çalışmaları, bölgede hidrotermal alterasyonun geliştiğini ve yan kayaçlarda serisitleşme, kloritleşme ve piritleşmenin yaygın olduğunu göstermektedir. Alterasyon jeokimyası çalışmalarında indeks değerleri (CIA); 15,72-85,90, klorit-karbonat-pirit indeksi (CCPI) değerleri; 56,94-98,51 ve alterasyon indeksi (AI) değerleri ise 13,51-98,05 arasındadır. Yan kayaçlarda gözlenen alterasyon eğilimi klorit+pirit+serisit şeklindedir.

Damar tipi şeklinde ve epijenetik oluşumlu cevher zonunda süksesyonun pirit, bornit, kalkopirit, kovellit, götit ve malakit şeklinde olduğu ve yapılan üç farklı doğrultudaki örneklendirmede Cu'nun $\% 2,45$ 'e (\% Ağırlık) ulaştı̆̆ belirlenmiştir.

Cevherleşmenin Orta Eosen yaşlı Maden grubuna ait diyabazlar içerisindeki süreksizlik düzlemleri boyunca yerleşmiş kuvars damarları ile ilişkili olarak gözlenmesi ve bu zonlarda hidrotermal alterasyonun yoğun olarak bulunması cevherleşmede yapısal kontolün etkin olduğunu ve cevher zonlarının kırık hatları ile sınırlı olduğunu göstermektedir.

\section{Yazarların Katkısı}

Genel Jeoloji, saha jeolojisi, cevher petrografisi ve maden jeolojisi çalışmaları sorumlu yazar tarafindan gerçekleştirilmiştir. Jeokimyasal analiz ve kayaç petrografisi çalışmaları ikinci ve üçüncü yazarlar tarafından yapılmıştır. Son yazar alterasyon jeokimyası çalışmalarını gerçekleştirmiştir.

\section{Çıkar Çatışması Beyanı}

Yazarlar arasında herhangi bir çıkar çatışması bulunmamaktadır.

\section{Araştırma ve Yayın Etiği Beyanı}

Yapılan çalışmada araştırma ve yayın etiğine uyulmuştur. 


\section{Kaynaklar}

[1] Seeliger T.C., Pernicka E., Wagner G.A., Begeman F., Schmitt-Strecker S., Eibner C., Öztunalı Ö., Barany1 I. 1985. Archo-metalurgische untersue-hungen ni Nord und Ostanatolien. 32. Jahbuch des Römisch. Germanischen Zentralmuseums, Mainz, Germany, 597-659.

[2] Tizlak E. 1991. Mining in the Keban-Ergani area (1780- 1850). Doktora Tezi, Frrat Üniversitesi, Fen Bilimleri Enstitüsü, Elazığ (in Turkish).

[3] Erdoğan B. 1977. Geology geochemistry and genesis of the sulphide deposits of the ErganiMaden region SE Turkey. PhD Thesis. University of New Brunswick,

[4] Özkaya İ. 1978. Stratigraphy of Ergani-Maden vicinity. Geological Bulletin of Turkey, 21: 129139.

[5] Özdemir Z., Sağıroğlu A. 1998. The Study of Biogeochemical Anomalies for Fe along the Maden River (Maden-Elazig). Geological Bulletein of Turkey, 41/1: 49-54.

[6] Özdemir Z., Sağıroğlu A. 2000. The Study of Biogeochemical Anomalies for Zn along the Maden River (Maden-Elazig). Mersin University, Series of Essay, 4: 93-100.

[7] Kırat G., Bölücek C., Kalender L. 2008. Distribution of $\mathrm{Cu}, \mathrm{Pb}, \mathrm{Zn}$, As $\mathrm{Cd}$ and $\mathrm{Fe}$ in stream sediments around of Maden copper deposit. Geosound/Yerbilimleri, 53: 203-217.

[8] Kalender L. 2012. Environmental impact and drainage geochemistry of the abandoned Keban Ag, $\mathrm{Pb}, \mathrm{Zn}$ deposit, In: Dionisions Panagiotaras (Ed.), Working Maden Cu Deposit and Alpine Type Cr Deposit in the Eastern Anatolia, Turkey. Geochemistry, Published by In Tech, Croatia, 345370.

[9] Sirel M.A. 1949. Die Kupferlagerstaette Ergani-Maden in der Turkei. N. Jh. Mineral. Abh. Abt. A., 80: 36-95.

[10] Borchert H. 1952. Ergani bakır cevheri yataklarında yapılan jeolojik tatbikata ait rapor. Yayımlanmamış rapor, Maden Tetkik ve Arama Genel Müdürlüğü (MTA), 2083 Ankara, Türkiye.

[11] Schneiderhöhn H. 1954. Ergani bakır yatağı, Yayımlanmamış rapor. Etibank Genel Müdürlüğü, 812, Ankara, Türkiye, 1-48.

[12] Göymen G., Aslaner M. 1969. Doğu Anadolu'da bulunan Ergani-Maden bakır yatağının ve bilhassa yantaşlarının maden mikroskopik incelenmesi. Maden Tetkik ve Arama Genel Müdürlüğü (MTA) Dergisi, 72: 176-188.

[13] Bamba T. 1976. Güneydoğu Anadolu Ergani-Maden bölgesi ofiyolit ve ilgili bakır yatağı. Maden Tetkik ve Arama Genel Müdürlüğü (MTA) Dergisi, 86: 35-49.

[14] İleri S., Salancı B., Bitem M., Doğan R. 1976. Ergani (Maden) copper deposit and plate tectonics. Bull. Geol Soc. Turk, 19: 133-142.

[15] Erdoğan T. 1975. VI. Bölge Gölbaşı Dolayının Jeolojisi. TPAO Rapor No: 929, Ankara (yayınlanmamış).

[16] Erler A. 1983. Tectonic setting of the massive sulphide deposit of the Southeast Anatolian thrust belt. In: Tekeli, O., Göncüoğlu, M.C. (Eds.), Geology of the Taurus Belt. General Directorate of Mineral Research and Exploration (MTA), Ankara, 309-316.

[17] Wijkerslooth P. 1944. Elazığ ili (Ergani-Maden) bakır yatakları hakkındaki bilgiye yeni bir ilave [New contribution to the understanding of Elazı $\breve{g}$ (Ergani-Maden) copper deposits]. Bull Min Res Exp, 33: 76-104.

[18] Çiftçi E. 2019. Volcanogenic Massive Sulfide (VMS) deposits of Turkey. In: Pirajno F., Ünlü T., Dönmez C., Şahin M. (eds) Mineral Resources of Turkey. Modern Approaches in Solid Earth Sciences, Springer, Cham., 16: 427-496.

[19] Constantinou G. 1980. Metallogenesis associated with the Troodos ophiolite. A. Panayiotu (Ed.). Ophiolites Proceeding International Ophiolite Symposium, 1980, Nicosia-Cyprus, 663-674.

[20] Richards H., Cann J., Jensenius J. 1989. Mineralogical zonation and metasomatism of the alteration pipes of Cyprus sulfide deposits. Econ Geol, 84 (1): 91-115.

[21] Yıldırım N., Dönmez C., Kang J., Lee I., Pirajno F., Yıldırım E., Günay K., Seo J.H., Farquhar J., Chang S.W. 2016. A magnetite-rich Cyprus-type VMS deposit in Ortaklar: a unique VMS style in the Tethyan metallogenic belt, Gaziantep, Turkey. Ore Geol Rev, 79: 425-442.

[22] Altun Y., Yilmaz H., Şiner İ., Yazar F. 2015. The secrets of massive sulfide deposits on midocean ridges and Küre-Mağaradoruk copper deposit. Bull Min Res Exp, 150: 51-64. 
[23] Şaşmaz A., Gümüş G., Sağıroğlu A. 1999. A typical example of allochtonous Cyprus type copper mineralizations: Derdere mineralizations. Geol Bull Turkey, 42 (1): 105-117.

[24] Akıncı Ö.T. 2009. Ophiolite-hosted copper and gold deposits of southeastern Turkey: formation and relationship with seafloor hydrothermal processes. Turk J Earth Sci, 18 (4): 475-509.

[25] Yıldırım N., İlhan S., Akyıldız M., Yıldırım E., Dönmez C. 2010. The importance of the ophiolites of the southern branch of the Neotethys (Koçali ophiolitic complex), in terms of the Cyprus Type VMS Deposits. In: 7th International symposium on Eastern Mediterranean Geology, Turkey, Adana.

[26] Yıldırım N., İlhan S., Yıldırım E., Dönmez C. 2012. The geology, geochemistry and genetical features of the Ormanbaşi Hill (Sincik, Adiyaman) copper mineralization. Bull Min Res Exp, 144: 75-104.

[27] Yildırım N., Parlak O., Robertson A.H.F. 2012. A Geochemistry and tectonic significance of the Koçali ophiolite and the related Koçali melange, Adiyaman region, SE Turkey. In: EGU General Assembly conference abstracts, 1253 .

[28] İlhan S. 2013. The origin of massive sulfide deposits within the Kocali Complex (Adiyaman). $\mathrm{PhD}$ thesis, Çukurova University, Institute of Natural and Applied Sciences, Adana, (in Turkish with English Abstract, unpublished).

[29] Akyıldız M., Yıldırım N., Gören B., Yı1dırım E., Ilhan S. 2015. The origin of vein-type copperlead-zinc deposits Host in Palaeozoic metamorphic rocks at the Southeast Anatolian Orogenic Belt (Küplüce-Adıyaman, Southeastern Turkey). J Afr Earth Sci, 102: 191-202.

[30] Ketin İ. 1983. An overview of the geology of Turkey. Istanbul Technical University Library Publication 1259, 1-595.

[31] Şengör A.M.C., Y1lmaz Y. 1981. Tethyan evolution of Turkey: a plate tectonic approach. Tectonophysics, 75 (3-4): 181-241.

[32] Robertson A.H.F., Ustaömer T., Pickett E.A., Collins A.S., Andrew T., Dixon J.E. 2004. Testing models of Late Palaeozoic-Early Mesozoic orogeny in Western Turkey: support for an evolving Open-Tethys model. J Geol Soc, 161 (3): 501-511.

[33] Okay AI. 2008. Geology of Turkey: a synopsis. Anschnitt, 21: 19-42.

[34] Yıldırım M. Yılmaz Y. 1991. Güneydoğu Anadolu orojenik kuşağının ekaylı zonu [Imbricated zone of the Southeast Anatolian Orogenic Belt]. Turkish Assoc Pet Geol Bull (TAPG), 3: 57-73.

[35] Y1lmaz Y. 1993. New evidence and model evolution of the southeast anatolian orogen. Geological Society of America Bulletin, 105: 251-271.

[36] Yılmaz Y., Yigitbaş E., Genç S. 1993. Ophiolitic and metamorphic assemblages of southeast Anatolia and their significance in the geological evolution of the orogenic belt. Tectonics, 12: 1280-1297.

[37] Ketin İ. 1948. Ergani Eğil bölgesinin jeolojik etüdü hakkında memuar. Maden Tetkik ve Arama Genel Müdürlüğü, Rap. No. 2015 (yayımlanmamış).

[38] Perinçek D., Özkaya İ. 1981. Arabistan levhası kuzey kenarının tektonik evrimi. Yerbilimleri, 8: 91-101.

[39] Yazgan E. 1983. A geotraverse Between the Arabian Platform and the Munzur Nappes. International Symposium on the Geology of the Taurus Belt, 17, 26-29 September, Ankara, 17p.

[40] Yazgan E. 1984. Geodynamic Evolution of the Eastern Taurus Region (Malatya-Elazı ğ area, Turkey). International Symposium on the Geology of the Taurus Belt, 26-29 September, Ankara, 199-208.

[41] Hempton M. 1985. Structure and deformation history of the Bitlis suture near Lake Hazar, SE Turkey. Geological Society of America Bulletin, 96: 223-243.

[42] Ertürk M.A., Beyarslan M., Chung S.-L., Lin T.H. 2018. Eocene magmatism (Maden Complex) in the Southeast Anatolian Orogenic Belt: Magma genesis and tectonic implications. Geoscience Frontiers, 9: 1829-1847.

[43] Aktaş G., Robertson A.H.F. 1990. Tectonic evolution of the tethys suture zone in SE, Turkey: Evidence from the petrology and geochemistry of late Cretaceous and Middle Eocene extrusives. In. Symposium On ophiolite genesis and evolution of oceanic lithosphere, Geological Society of London Special Publications, 311-328. 
[44] Açıkbaş D., Baştuğ C. 1975. V. Bölge Cacaz-Hani Yöresi Kuzey sahalarının jeoloji raporu ve petrol olanaklar1 [Geology survey report and petroleum potentials of V. Region Cacaz-Hani area northern territories]. TPAO Raport No: 917 (in Turkish, unpublished).

[45] Perinçek D. 1979. Palu-Karabegan-Elazığ-Sivrice-Malatya alanının jeolojisi ve petrol imkânları. Türkiye Petrolleri Anonim Ortaklığı, Rap. No. 1361.

[46] Robertson A.H.F., Parlak O., Rızaoğlu T., Ünlügenç U.C., Inan N., Taslı K., Ustaömer T. 2007. Tectonic evolution of the South Tethyan ocean: evidence from the Eastern Taurus mountains (Elazığ region, SE Turkey). Geological Society of London Special Publications, 272: 233-272.

[47] Erdoğan B. 1982. Ergani-Maden Yöresindeki Güneydoğu Anadolu Ofiyolit kuşağının jeolojisi ve volkanik kayaçları. Türkiye Jeoloji Kurumu Bülteni, 25: 49-50.

[48] Işık V. 2016. Torosların Jeolojisi; Türkiye Jeolojisi Ders Notu. Ankara Üniversitesi, Jeoloji Mühendisliği Bölümü, Ankara.

[49] Mineral Research and Exploration (MTA), 2002. 1/500.000 scale geological maps of Turkey. General Directorate of Mineral Research and Exploration (MTA), Ankara, Turkey.

[50] Ishikawa Y., Sawaguchi T., Iwaya S., Horiuchi M. 1976. Delineation of Prospecting Targets for Kuroko Deposits Based on Modes of Volcanism of Underlying Dacite and Alteration Haloes. Mining Geology, 26: 105-117.

[51] Large R.R., Gemmell J.B., Paulick H., Huston D.L. 2001. The alteration box plot: A simple approach to understanding the relationship between alteration mineralogy and lithogeochemistry associated with volcanichosted massive sulfi de deposits: Economic Geology and the Bulletin of the Society of Economic Geologists, 96: 957-971.

[52] Nesbitt H.W., Young G.M. 1982. Early Proterozoic climates and plate motions inferred from major element chemistry of lutites. Nature, 299: 715-717.

[53] Nesbitt H.W., Young G.M. 1989. Formation and diagenesis of weathering profiles: The Journal of Geology, 97: 129-147.

[54] Üstüntaş A., Sağıroğlu A. 1993. Zahuran (Maden-Elazığ) yöresindeki iki farklı tip $\mathrm{Cu}$ cevherleşmesi. Türkiye Jeoloji Kurumu Bülteni, 36: 179-188. 